\title{
Sri Lanka Association of Urological Surgeons
}

Joint Academic Meeting of the Sri Lanka Association of Urological Surgeons (SLAUS) with the Section of Urology of the Royal Society of Medicine (RSM), United Kingdom was held at the Cinnamon Lakeside Hotel, Colombo, Sri Lanka on 27-28 November 2009. This landmark event was held to celebrate the 10th Anniversary of the SLAUS. The meeting featured some outstanding lectures by several internationally and locally recognized experts in the field of urology. The sessions were preceded by some excellent pre-congress workshops. The highlights of the superb academic programme are listed below.

- Pre-congress workshop on the management of Urinary Tract Injuries on 23 November 2009 at Skills Lab, University of Sri Jayawardenapura, Gangodawila, Nugegoda Faculty: Peter Tohompson, Ian Dickinson and Chris Parker

- Masterclass in Paediatric Urology on 23 November 2009 at the Lady Ridgeway Hospital, Colombo Faculty: Supul Hennayake

- Masterclass in Urolithiasis on 24 November 2009 at the Department of Surgery Auditorium, National Hospital of Sri Lanka, Colombo

Faculty: Byron Walmsley and Graham Watson

- Masterclass in Paediatric PCNL and Laparoscopy on 25 November 2009 at the Department of Surgery Auditorium, National Hospital of Sri Lanka, Colombo Faculty: Byron Walmsley and Graham Watson

- Masterclass in Urogynaecology on 26 November 2009 at the Lanka Hospitals Auditorium, Colombo Faculty: Roland Morley, Roger Walker and Tom Rosenbaum

Inaugural ceremony was held on 26 November at 18:30 with the Presidential Address (SLAUS) delivered by Serozsha A.S. Goonewardena on the 'History of Urology in Sri Lanka' and the Presidential Address (RSM) delivered by Peter Thompson.

The SLAUS Lecture was given by Peter Thompson on 'Evolution and safety of prostate biopsy'

The UK Faculty comprised Ralph Beard, Aine Burns (Nephrologist), Ian Dickinson, Michael Dineen, Supul Hennayake, David Jones, Roland Morley, Chris Parker (Secretary, RSM), Tom Rosenbaum, Nick Thomas (Neurosurgeon), Peter Thompson (President, Urology Section of the RSM), Roger Walker, Byron Walmsley and Graham Watson.

Ching Chong Ming of Singapore participated at the sessions delivering two lectures.
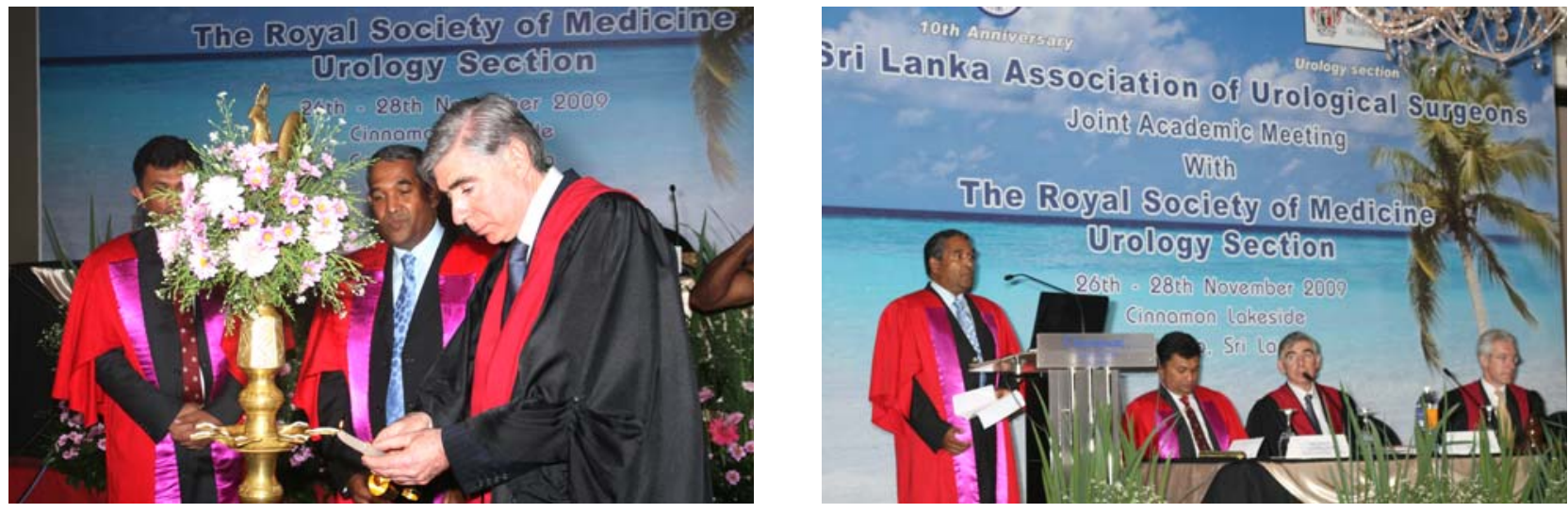

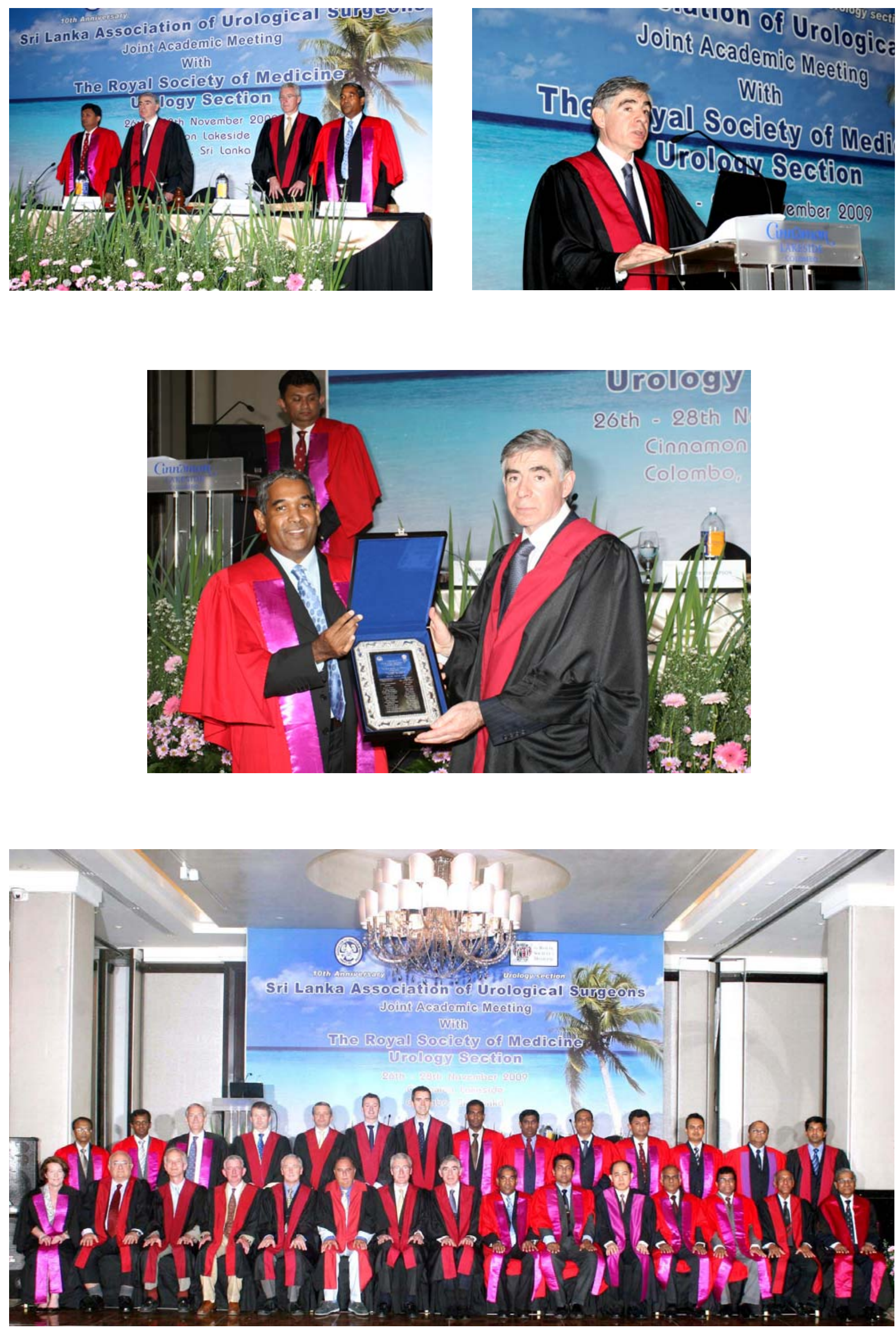